\title{
Training Mode on Graduation Design of Engineering Students Based on the Dual-Tutor System
}

\author{
X.D. Yuan \\ Materials Science and Engineering Institute \\ Shandong Jianzhu University \\ Jinan, Shandong
}

\author{
X. Liu \\ Shandong Product Quality Inspection Research Institute \\ Jinan, Shandong
}

\author{
G.L. Yuan \\ Jinan Engineering Quality and Work Safety Supervision Station \\ Jinan, Shandong
}

\begin{abstract}
The dual-tutor system is a training model. The Institute of Materials Science and Engineering of Shandong Jianzhu University began to carry out the dual-tutor system in 2006 to improve the quality of cultivating students and to strengthen the construction of connotation. The training mode on graduation design of engineering students based on the dual-tutor system was mainly discussed in this paper. The importance of the reform of graduation design was investigated through the innovation of traditional graduation design, the graduation design mode of university-industry cooperation and the effect analysis on graduation design. It is proved that the training mode based on the dual-tutor system has remarkable effects on graduate design, which provides a new way of thinking to the construction of academy connotation.
\end{abstract}

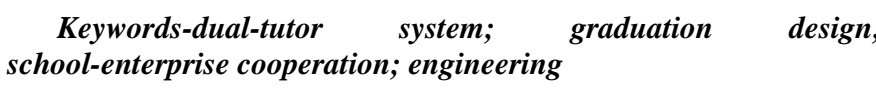

\section{INTRODUCTION}

The dual-tutor system originated from Oxford of England, which is a new talents training model. The dual-tutor system of Oxford brought new enlightenment to talents training of Chinese universities. In 2002, Peking University began to try the dual-tutor system as an experimental unit. Afterwards, various "similar tutor systems" are produced, for example, Master tutor system, Doctor tutor system, Head teachers system, Whole tutor system, Whole course tutor system, Research-type tutor system, etc [1]. Graduate design is the last course in the process of achieving the training objectives, which is also a test for the knowledge that undergraduates have learned in four years. In a sense, the quality of graduation design directly proves whether the training objective in the past four years is successful or not. Currently, the managements of graduation design under a variety of tutorial systems are not really the same. There is insufficiency in different Sponsored by the Research degree selecting a topic aimlessly for students, the design structure is unclear, lacking of theoretical knowledge, processing data is unscientific, experiment workload is too small, lacking of standardization in writing papers, etc. [2-6]. Given the status of traditional graduate design, this paper takes Materials Science and Engineering of Shandong Jianzhu University as an example to explore and analyze the training mode of graduation design based on the dual-tutor system.

\section{TRAINING SySTEM OF DUAL-TUTOR SYSTEM}

\section{A. Implementation Process of the Dual-Tutor System}

The implementation process of the dual-tutor system is shown in Figure 1. It can be seen in Figure 1 that the tutors of freshman and sophomore are mostly counselors, who mainly take charge of students' life, learning, taking a part-time job for their study, party building, and campus culture and so on. During the freshman year, counselor divides students into different interest groups of scientific research based on the classification and their interest in their major direction, inviting different experts and professors with higher level of scientific research to give lectures according to different interest groups of scientific research; during the sophomore year, counselor carries out a series of Design Competitions about students' career planning and Design Competitions about students' study arrangements according to different interest groups of scientific research, helping students to identify good scientific research interest and build self-confidence.

The students' tutors are mainly young teachers in junior and senior years, who mainly take charge of guiding students' major, cultivating their professional interests, improving the level of scientific research and instructing graduation design. In the first semester of junior year, the principle of "two-way selection" is adopted to carry out mutually selection between students and tutors. Students select their tutors based on major interests of their own and the research direction of teachers; teachers select students according to requirement of their issues and students' performance. During the junior year, the tutors should actively encourage and guide students to participate in the nationwide undergraduates "Challenge Cup" Competition, leading students to take part in "substituted post exercitation" in summer social practice and "open tests" activities of academy in order to lay a solid foundation for students' graduation design. 


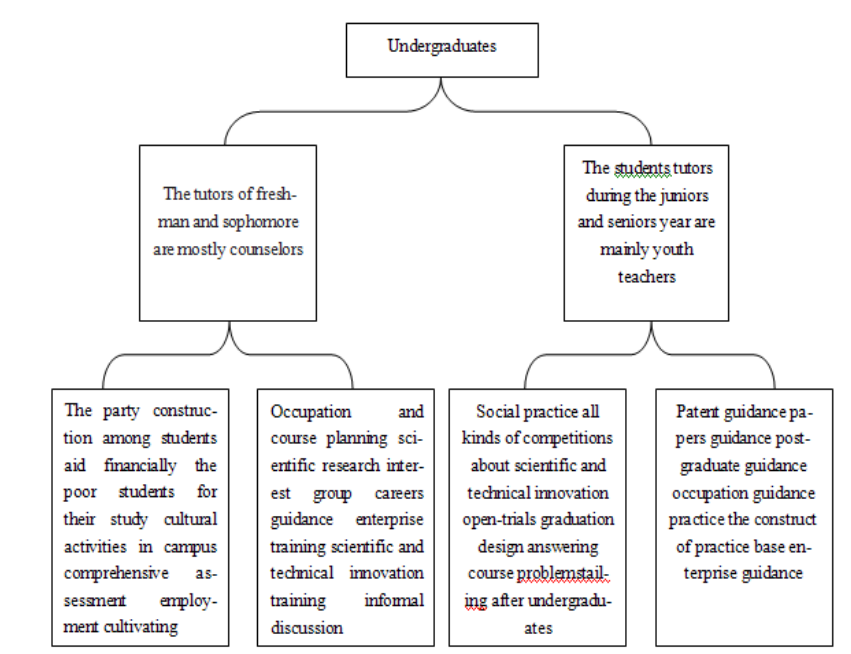

FIGURE I. IMPLEMENTATION PROCESS OF THE DUAL-TUTOR SYSTEM.

\section{B. The Evaluation System on the Dual-Tutor System}

To ensure the smooth implementation of dual-tutor system, and to keep it developing healthily, academy has established a set of scientific evaluation systems and has improved the dual-tutor system by methods of self-evaluation, students' assessment and comprehensive evaluation. And each of these three methods accounts for different proportions, whose results are generally classified into excellent, good, qualified and disqualified. On one hand, final evaluation results are regarded as a teacher's work performance. At the end of year, the teachers are given certain advantages and set the examples. On the other hand, final evaluation results are served as the content of assessing teachers titles work performance. And the teachers are given certain superiority. The principles of dynamic management, directional management and scientific management are adopted to enrich the dual-tutor system, to help the teachers by qualitative and quantitative guidance, to inspire teachers to broaden their horizons, to help students to focus on scientific facts, and to guide students to explore the peaks of science. There are certain reports in this area at home [7].

\section{The Training Mode On Graduation Design}

\section{A. The Conventional Situation o Traditional Graduate De- sign}

The graduation design is an important part in the undergraduate teaching system. The quality of graduation design directly affects the quality of training students. There are some problems existing in traditional graduate design, for example, the content of topics and the content of scientific research projects are inconsistent, which results in less teachers' input, unseriousness, and blindness. The required equipment in the process of carrying out the graduation design is insufficient, which results in students' poor operation ability, the experimental program being not fully implemented, and students' scientific design greatly restricted. The management system of graduate design is unsound, leading to many consequences like tutors are inattentive, and can't work actively, students are not serious and the workload is low. Tutors' workload is heavy and tutors have fewer opportunities to communicate with students. Students' valid resources are fewer. The quality of graduation design is poor. The traditional graduate design is not in accordance with schools' standards, resulting in nonstandard graduation design writing, unscientific data processing, and unprofessional research habits and so on.

\section{B. The Innovation Mode of Graduation Design}

Given the shortcomings of traditional graduation design, the Institute of Materials Science and Engineering of Shandong Jianzhu University has established a more scientific training and management mode for graduate design in the work requirements of dual-tutors system. The specific content is shown in Figure 2 and Figure 3. As we can see from the chart, graduation design time directed by tutors on campus is lengthened from half a year to one year. The students and tutors determine the topic and content of graduation design together based on students' research interests and tutors' research project with tutors' standard management, rigid attendance, serious guidance and students' serious attitude to study, deep thought and open innovation ability. In addition, in order to improve students' work ability and graduation design quality, the Institute of Materials Science and Engineering tries to adopt the university-enterprise cooperation mode to carry out the graduation design, to help communication between intramural tutors and enterprise tutors, and to help students to accomplish graduation design requirements together. There are also related graduation designs reports on school-enterprise cooperation [8].

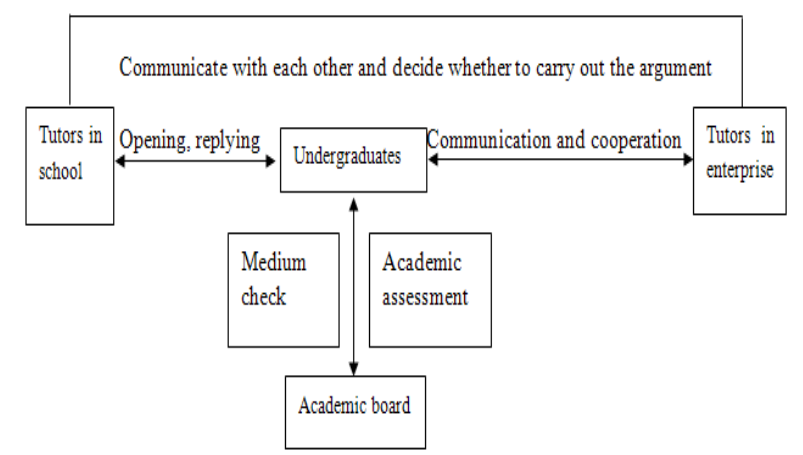

FIGURE II. THE MANAGEMENT MODE OF GRADUATION DESIGN.

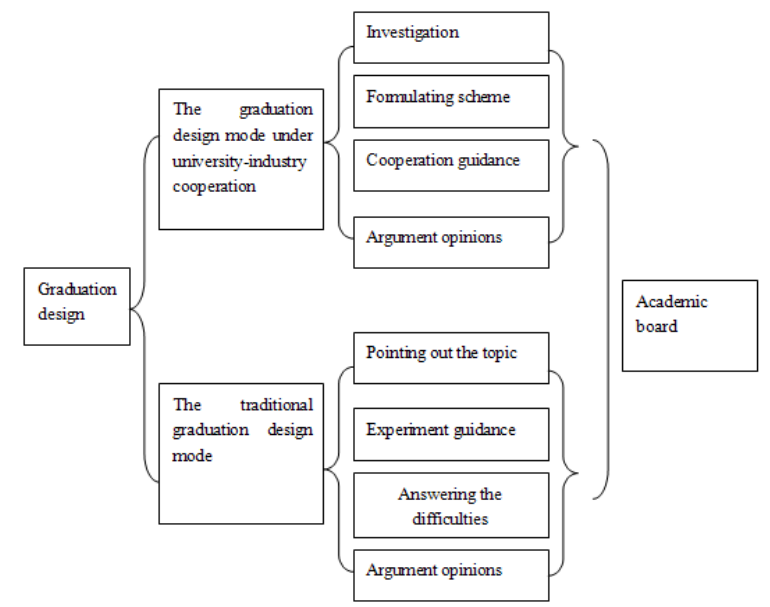

FIGURE III. THE TRAINING MODE OF GRADUATION DESIGN. 


\section{The EFFECt ANALysis of GRADUATION DESIGN BASED ON THE DUAL- TUTOR SYSTEM}

\section{A. Students' Confidence at Work is Improved}

Compared with the traditional graduation design, the effects on the innovation of graduate design is remarkable because of the dual-tutor system. The reform and innovation of intramural graduation design give students enough time to carry out graduation design. Students are able to think deeply, to perfect scheme, to study fully, and to strengthen theory. Students' practice abilities at work and their confidence to work after graduation are enhanced while students' graduation design quality is improved. The school-enterprise cooperation model improves and trains most of students' abilities at least three aspects, namely the ability of linking theory with practice, the ability of engineering drawings, and the ability of self-management. The improvement of these capabilities is bound to play an important role in students practice work.

\section{B. The Structure of Graduation Design is Improved}

Due to the influence of traditional graduation design, tutors choose the topic for graduation design based primarily on their professional advantages. Because of this choosing method, tutors can only study what they are already skilled at. However, the new training mode, especially the implementation of school-enterprise cooperation in training mode, improves the structure of graduation design, and broadens the horizons of professional instructors by obtaining external practice information of scientific research.

\section{The Level of Teachers' Scientific Research is Improved}

The development of graduation design of school-enterprise cooperation improves the structure of graduation design, and avoids the flaw of traditional graduation design. At the same time, tutors' research perspective, research ideas and research attitude are also changed. Tutors can correctly judge the practicality of scientific research project, adjust research ideas and increase available research content, thereby increasing the level of research work.

\section{CONCLUSIONS}

The training mode of the graduation design based on the dual-tutor system was experimented by Shandong Machinery Industry Association, Shandong Province Surface Engineering Association, and the province's major machinery manufacturing. The quality of graduation design and students' ability to get a job are improved. Teachers' research horizons are also broadened. The quality of teachers' research work is enhanced. Practice has proved that the feasibility of the training mode on graduation design based on the dual-tutor system is powerful. The effect of the training mode is significant. This kind of training mode should be widely implemented.

\section{ACKNOWLEDGEMENT}

Fund for the College science and technology plan of Shandong Province (Project No. J12LA11).

\section{REFERENCES}

[1] Wenqiang Zheng, Qian Ding. First exploration on how the research-tutors affect the scientific research level of undergraduates, The academic journal of Henan Staff Medical College. 23 (2011) 762-763.
[2] Fulin Teng, Jianhua Wang. How the tutor system influencing the quality of the graduation design of undergraduates, Chinese modern education and equipment. 17 (2011)140-141.

[3] Yanghua Ou, Yunqin Shen. The exploration and thought on how to improve graduation design quality of undergraduates, The innovation on technology and education. 15 (2011)201-203.

[4] Zhuojuan Yang, Xiaodong Yang. Differentiate and analyze the existence or abolishment of graduation design, Research on Higher Education in Heilongjiang. 9 (2011)160-162.

[5] Zhenyu Wang. The discussion on how improve the Improve the graduation design quality of engineering undergraduate, The innovation on science and technology. 30 (2011)176-177.

[6] Shuhong Xu, Shouzan Liu. The construct on evaluation index system of tutor system about undergraduate in high schools, Education in Heilongjiang province. 8 (2010)19-21.

[7] Xiaokai Xing, Changchun Wu. Practice and exploration on the graduation design directed by school-enterprise cooperation of research university, Educational reform. 5 (2011)84-86.

[8] Lingfeng Zhang, Jiuba Wen,etc. The training mode on undergraduates graduation design who are in the universities of school-enterprise cooperation based on the enterprise, Chinese modern education and equipment. 19 (2011)106-108. 